\title{
COMUNICAÇÃO
}

\section{CLASSIFICAÇÃO E TENDÊNCIAS CLIMÁTICAS EM LAVRAS, MG}

\author{
Climatic classification and tendencies in Lavras region, MG
}

\author{
Antonio Augusto Aguilar Dantas ${ }^{1}$, Luiz Gonsaga de Carvalho², Elizabeth Ferreira ${ }^{3}$
}

\begin{abstract}
RESUMO
Objetivou-se com este trabalho avaliar a tendência de dados climáticos nos últimos 14 anos, na região de Lavras, MG, comparando-os com aqueles da série histórica do período de 1961 a 1990. Foi utilizado o método do balanço hídrico de Thornthwaite \& Mather (1955)para os dados do período de 1961-1990 e para os dados recentemente observados de 1991-2004. O método do balanço hídrico de Thornthwaite considera a evapotranspiração potencial, a precipitação pluvial, o armazenamento de água no solo e seu subsequente uso. Este método também apresenta os períodos de excesso e deficiência hídrica, então utilizados no método de classificação climática de Thornthwaite para determinar os índices de umidade e de aridez. Os índices resultaram na fórmula climática de Thornthwaite que nesta comparação, mudou de $\mathrm{B}_{3} \mathrm{r} \mathrm{B}_{3} \mathrm{a}^{\prime}$ para $\mathrm{B}_{2} \mathrm{r} \mathrm{B}_{3}$ a' no período mais recente. A classificação climática de Köppen, também utilizada neste trabalho não apresentou diferenças para ambos os períodos, permanecendo $C w a$.
\end{abstract}

Termos para indexação: Climatologia, balanço hídrico, classificação climática.

\begin{abstract}
The purpose of this study was to evaluate the climatic data tendency in the last 14 years of monthly rainfall and temperatures in Lavras region, MG state , compared to those of the historical series of 1961-1990 period. The Thornthwaite's water balance method was employed for the climatological data of 1961-1990 and for the last observed data of 1991-2004. The Thornthwaite's \& Mather's water balance method considers the potential evapotranspiration, the rainfall, the storage of water in the ground and its subsequent use. This method also shows hidric excess and deficiency periods, then used on the Thornthwaite's climatic classification method to determine the moisture and aridity index of the climate. The index resulted on the Thornthwaite's climatic formula wich changed from $\mathrm{B}_{3} \mathrm{r} \mathrm{B}_{3} \mathrm{a}^{\prime}$ to $\mathrm{B}_{2} \mathrm{r} \mathrm{B}_{3} \mathrm{a}^{\prime}$ in the most recent reiod. The Köppen climatic classification method, also employed in this work, showed no changes, remaining Cwa for both periods.
\end{abstract}

Index terms: Climatology, water balance, climatic classification methods.

\section{(Recebido em 4 de novembro de 2005 e aprovado em 15 de março de 2007)}

As atividades agrícolas, devido às variações dos elementos climáticos, estão sempre expostas a riscos e insucessos. Dentre os elementos climáticos, a precipitação pode apresentar grande variabilidade. Neste caso, o excesso ou falta de água afeta o sistema solo-plantaatmosfera e reduz a produtividade agrícola. $\mathrm{O}$ balanço hídrico climatológico é um método contábil que fornece o saldo de água disponível no solo, em outras palavras, contabiliza a entrada e saída de água numa região. A partir destes cálculos torna-se simples fazer-se a classificação climática, porque os dados necessários são justamente variáveis já determinadas na resolução do balanço hídrico. $\mathrm{Na}$ metodologia são empregados apenas dados de temperatura do ar e de precipitação pluvial. Também é um critério muito apropriado para definir as características climáticas do local e para tanto se utilizam os valores médios mensais normais. Os estudos de balanços hídricos devem ser desenvolvidos visando a relação cultura/clima, o que permite um ajuste do cultivo às condições climáticas, evitando as consequências desastrosas de um planejamento agrícola deficiente com relação ao clima (TUBELIS, 1988).

Porém, de acordo com Adger et al. (2007) as evidências observadas a partir de todos os continentes e dos oceanos, mostram que muitos sistemas naturais estão sendo afetados por mudanças climáticas regionais, particularmente aumentos de temperaturas. As principais diferenças observadas são: mudanças no gelo, na neve e no permafrost das regiões polares, aumentos nos derretimentos de geleiras agravados pela ocorrência

\footnotetext{
${ }^{1}$ Habilitado em Técnicas Agropecuárias, Doutor - Departamento de Engenharia/DEG - Universidade Federal de Lavras/UFLA - Cx. P. 3037 - $37200-000$ Lavras, MG - aadantas@ufla.br

${ }^{2}$ Engenheiro Agrícola, Doutor - Departamento de Engenharia/DEG - Universidade Federal de Lavras/UFLA - Cx. P. 3037 - $37200-000$ - Lavras, MG -

Igonsaga@ufla.br bethf@ufla.br
}

Ciênc. agrotec., Lavras, v. 31, n. 6, p. 1862-1866, nov./dez., 2007 
precoce da primavera, aquecimento de lagos e rios em muitas regiões, alterando a estrutura térmica e a qualidade da água, adiantamento da primavera, alterando a formação de folhas nas árvores e a migração de pássaros, alterações nos habitats, deslocando espécies vegetais e animais para regiões outrora mais frias, aumento de algas, plâncton e peixes em oceanos situados em regiões de altas latitudes, aumento de algas e plâncton em lagos situados em regiões de altas latitudes e migração antecipada de peixes. Também estão relacionados os efeitos na agricultura e nas florestas situadas no hemisfério norte como a antecipação da primavera e seu efeito na cultura de grãos e distúrbios florestais como incêndios frequentes e graves. Por outro lado, na África, aquecimento, secas e mudanças nas estações estão reduzindo as culturas agrícolas. Isto tudo, atribuído ao aquecimento global, por sua vez creditado principalmente ao incremento das concentrações do dióxido de carbono na atmosfera terrestre.

Neste trabalho, independente das causas que estejam alterando o clima, já que a classificação climática de uma região não entra neste mérito, efetuou-se o balanço hídrico climatológico com os valores obtidos das Normais Climatológicas, Brasil (1992) e com os dados médios observados nos últimos 14 anos em Lavras, MG, objetivandose identificar possíveis mudanças nas variáveis climáticas.

O balanço hídrico para o município de Lavras, de coordenadas geográficas, latitude $21^{\circ} 14^{\prime} \mathrm{S}$, longitude $45^{\circ}$ 00’W Gr. e 918 m de altitude, foi calculado segundo o método proposto por Thornthwaite \& Mather (1955), para uma capacidade de água disponível de $100 \mathrm{~mm}$, com a evapotranspiração potencial sendo estimada pelo método de Thornthwaite (1948) que considera as temperaturas médias mensais para estimar a evapotranspiração potencial baseando-se em índices de calor a partir das temperaturas médias mensais. Para o balanço hídrico considerado neste trabalho, foram utilizados dados meteorológicos mensais de temperaturas médias do ar e precipitações, obtidos na Estação Climatológica Principal de Lavras, convênio UFLA/ INMET, durante o período de 1991 a 2004. No balanço hídrico climatológico, de 1961 a 1990, foram utilizados os dados constantes das Normais Climatológicas, Brasil (1992), os quais, por sua vez, também foram calculados a partir das observações realizadas na mesma Estação Climatológica. A análise climática foi realizada utilizando-se a metodologia para a classificação climática proposta por Köppen conforme Pereira et al. (2002) e Vianello \& Alves (1991) e a metodologia para a classificação climática proposta por THORNTHWAITE (1948), para verificar possíveis discrepâncias entre a série normal de dados 1961-1990 Brasil (1992) e a série recente 1991-2004 obtida a partir dos dados coletados na Estação Climatológica Principal de Lavras, convênio INMET/UFLA. Ressalva-se que a última é uma série incompleta, pois contém apenas 14 anos de dados. Finalmente os balanços hídricos foram comparados e também as classificações climáticas foram obtidas e comparadas.

As temperaturas e as precipitações pluviais das séries de 1961-1990 e 1991-2004 são apresentadas no Quadro 1. Os principais dados obtidos nos balanços hídricos para o município de Lavras, MG, são apresentados nos Quadros 2 e 3. A temperatura média anual normal era $19,4{ }^{\circ} \mathrm{C}$, variando de $15,8{ }^{\circ} \mathrm{C}$ em julho a $22,1^{\circ} \mathrm{C}$ em fevereiro. Para a série observada de 1991-2004, os valores das temperaturas ficaram maiores. A temperatura média anual aumentou para $20,4{ }^{\circ} \mathrm{C}$, variando agora de $17,1^{\circ} \mathrm{C}$ em julho a $22,8{ }^{\circ} \mathrm{C}$ em fevereiro. Os valores estão maiores, mas não se pode precisar os porquês: El Niño/Oscilação Sul? Aquecimento global? Alteração climática cíclica? Tendência apenas dos 14 anos que ainda poderá se reverter quando a série se completar (30 anos)? É arriscado fazerse considerações nestes termos!

O total de precipitação normal anual de $1530 \mathrm{~mm}$, reduziu-se para $1460 \mathrm{~mm}$ na série observada de 14 anos. Os extremos porém, se acentuaram quando comparados. A maior e a menor precipitação mensal normal eram respectivamente $296 \mathrm{~mm}$ em dezembro e $23 \mathrm{~mm}$ em julho. Para a série recente observada, os totais mensais agora são: $321 \mathrm{~mm}$ em janeiro e $7 \mathrm{~mm}$ em julho.

O balanço hídrico climatológico realizado para a série histórica normal do período de 1961-1990 apresentava uma evapotranspiração potencial (ETP) com $899 \mathrm{~mm}$, uma evapotranspiração real, (ETR) com $869 \mathrm{~mm}$, uma deficiência hídrica, (DEF) com 30 mm, um excesso hídrico, (EXC) com 661 mm, o índice hídrico, (Ih) igual a 73,5, o índice de aridez, (Ia) igual a 3,3, o índice de umidade, (Iu) igual a 71,5 e a relação evapotranspiração potencial de verão sobre a evapotranspiração potencial anual, (ETPv / ETP) igual a $31 \%$.

Como resultado do balanço hídrico para a série observada 1991-2004, obteve-se a ETP com 956 mm, a ETR com 873 mm, a DEF com $83 \mathrm{~mm}$, o EXC com 587 mm, o Ih igual a 61,4, o Ia igual a 8,7, o Iu igual a 56,2 e a relação ETPv / ETP igual a $31 \%$.

De acordo com a classificação climática proposta por Thornthwaite, para os dados da série normal (1961-1990), o clima de Lavras é $\mathbf{B}_{\mathbf{3}} \mathbf{r} \mathbf{B}^{\prime}{ }_{\mathbf{3}} \mathbf{a}^{\prime}$, ou seja clima úmido, com pequena deficiência de água, denominado mesotérmico, com uma ETP de $899 \mathrm{~mm}$ no ano, sendo que $31 \%$ desta ETP ocorre no verão. Para os dados observados no período de 1991-2004, o clima de Lavras é $\mathbf{B}_{\mathbf{2}} \mathbf{r} \mathbf{B}_{\mathbf{3}}{ }_{\mathbf{3}} \mathbf{a}$ ', ou seja clima úmido, com pequena deficiência de água, também mesotérmico, e com uma ETP de $956 \mathrm{~mm}$ no ano, sendo que $31 \%$ desta ETP ocorre no verão. 
Quadro 1 - Temperaturas médias mensais (T) e totais médios de precipitações (P) em Lavras, nos períodos de 1961-1990 e 1991-2004.

\begin{tabular}{|l|c|c|c|c|}
\hline & $1961-1990$ & $1991-2004$ & $1961-1990$ & $1991-2004$ \\
\hline Mês & $\mathrm{T}\left({ }^{\circ} \mathrm{C}\right)$ & $\mathrm{T}\left({ }^{\circ} \mathrm{C}\right)$ & $\mathrm{P}(\mathrm{mm})$ & $\mathrm{P}(\mathrm{mm})$ \\
\hline Janeiro & 21,7 & 22,6 & 272 & 321 \\
\hline Feveriro & 22,1 & 22,8 & 192 & 168 \\
\hline Março & 20,9 & 22,1 & 174 & 48 \\
\hline Abril & 18,8 & 21,0 & 67 & 56 \\
\hline Maio & 17,5 & 18,2 & 41 & 16 \\
\hline Junho & 16,3 & 17,1 & 28 & 15 \\
\hline Julho & 15,8 & 17,1 & 23 & 56 \\
\hline Agosto & 17,7 & 18,6 & 25 & 110 \\
\hline Setembro & 19,0 & 20,2 & 73 & 191 \\
\hline Outubro & 20,4 & 21,4 & 126 & 254 \\
\hline Novembro & 20,9 & 21,7 & 213 & 1460 \\
\hline Dezembro & 21,1 & 22,2 & 296 & 1530 \\
\hline Ano & 19,4 & 20,4 & & 16 \\
\hline
\end{tabular}

Quadro 2 - Evapotranspirações (ETP) mensais em Lavras, nos períodos de 1961-1990 e 1991-2004.

\begin{tabular}{|l|c|c|c|c|}
\hline & $1961-1990$ & $1991-2004$ & $1961-1990$ & $1991-2004$ \\
\hline Mês & ETP(mm) & ETP(mm) & ETR(mm) & ETR(mm) \\
\hline Janeiro & 102 & 108 & 102 & 97 \\
\hline Fevereiro & 93 & 97 & 87 & 95 \\
\hline Março & 87 & 95 & 72 & 74 \\
\hline Abril & 72 & 78 & 54 & 36 \\
\hline Maio & 55 & 56 & 41 & 26 \\
\hline Junho & 45 & 46 & 36 & 60 \\
\hline Julho & 44 & 48 & 41 & 92 \\
\hline Agosto & 58 & 61 & 68 & 95 \\
\hline Setembro & 68 & 74 & 86 & 106 \\
\hline Outubro & 86 & 92 & 91 & 873 \\
\hline Novembro & 91 & 95 & 98 & 869 \\
\hline Dezembro & 98 & 106 & & 96 \\
\hline Ano & 899 & & & 96 \\
\hline
\end{tabular}


Quadro 3 - Deficiências (DEF) e excessos hídricos (EXC) mensais em Lavras, nos períodos de 1961-1990 e 1991-2004.

\begin{tabular}{|l|c|c|c|c|}
\hline & $1961-1990$ & $1991-2004$ & $1961-1990$ & $1991-2004$ \\
\hline Mês & $\mathrm{DEF}(\mathrm{mm})$ & $\mathrm{DEF}(\mathrm{mm})$ & $\mathrm{EXC}(\mathrm{mm})$ & $\mathrm{EXC}(\mathrm{mm})$ \\
\hline Janeiro & 0 & 0 & 170 & 213 \\
\hline Fevereiro & 0 & 0 & 99 & 121 \\
\hline Março & 0 & 0 & 87 & 73 \\
\hline Abril & 0 & 4 & 0 & 0 \\
\hline Maio & 1 & 0 & 0 & 0 \\
\hline Junho & 4 & 10 & 0 & 0 \\
\hline Julho & 8 & 22 & 0 & 0 \\
\hline Agosto & 17 & 33 & 0 & 0 \\
\hline Setembro & 0 & 14 & 0 & 0 \\
\hline Outubro & 0 & 0 & 0 & 32 \\
\hline Novembro & 0 & 0 & 107 & 148 \\
\hline Dezembro & 0 & 0 & 198 & 587 \\
\hline Ano & 30 & 83 & 661 & 0 \\
\hline
\end{tabular}

Percebeu-se com base nestes resultados, a ocorrência de alteração no índice $\mathbf{B}_{3}$ que mudou para $\mathbf{B}_{2}$, ainda classificado como úmido. Este elemento da fórmula climática se refere ao índice de umidade Iu que expressa o tipo climático e tem 9 classificações. O tipo $\mathbf{B}_{3}$ se ajusta para um Iu entre 60 e 80, mas o tipo $\mathbf{B}_{2}$ se ajusta para um Iu entre 40 e 60, o que representa um tipo menos úmido que o anterior. Pode-se também observar que a deficiência hídrica anual mais que dobrou, passando de $30 \mathrm{~mm}$ na série histórica para $83 \mathrm{~mm}$ na série mais recente.

O clima de Lavras, segundo a classificação climática de Köppen, é Cwa, temperado chuvoso (mesotérmico) com inverno seco e verão chuvoso, subtropical, com inverno seco e temperatura do mês mais quente maior que $22{ }^{\circ} \mathrm{C}\left(22,1^{\circ} \mathrm{C}\right.$ em fevereiro). Para a série recente observada, a classificação permaneceu igual, mas a temperatura do mês mais quente que é considerada como referência para determinar a variedade específica de temperatura a, aumentou para $22,8^{\circ} \mathrm{C}$ em fevereiro, uma diferença de $0,7^{\circ} \mathrm{C}$. Ainda assim, esta classificação mantém a fórmula $\mathbf{C w a}$.

Estudos realizados por Hansen et al. (2006) com dados de temperaturas globais, nos últimos 100 anos, mostraram variações de $0,8{ }^{\circ} \mathrm{C}$ para o último século e $0,6{ }^{\circ} \mathrm{C}$ para as últimas 3 décadas. Verificando-se os totais anuais de temperaturas de Lavras, independentemente de se considerar as classificações climáticas, observa-se um aumento de exatamente $1^{\circ} \mathrm{C}$, (a temperatura média anual aumentou de $19,4{ }^{\circ} \mathrm{C}$ para $20,4{ }^{\circ} \mathrm{C}$ com relação aos períodos analisados). Isso mostra que mesmo com metodologias totalmente diferentes, pode-se detectar variações nos aumentos das temperaturas médias, comparando-se as temperaturas médias anuais das séries mais recentes com as séries anteriores.

Analisando-se os balanços climatológicos e as classificações climáticas realizadas sobre as séries de dados (1961-1990 e 1991-2004), considerando-se a série normal (1961-1990) como base, pode-se concluir que ocorreram mudanças na série mais recente onde as temperaturas médias mensais aumentaram, sendo que os totais de precipitações mensais na série mais recente apresentaram diminuição. A classificação climática por Thornthwaite, para a série mais recente, alterou-se, de $\mathbf{B}_{3} \mathbf{r} \mathbf{B}_{3}{ }_{3} \mathbf{a}^{\prime}$ para $\mathbf{B}_{2} \mathbf{r} \mathbf{B}{ }_{3} \mathbf{a}^{\prime}$, apresentando um índice $\left(\mathbf{B}_{2}\right)$ que representa uma umidade menor. Ressalta-se porém, que para todos efeitos, a classificação que ainda deve ser considerada, é a relativa aos Dados Normais, de 1961-1990 igual a B $\mathbf{3} \mathbf{r}$ B' ${ }_{\mathbf{3}}$ a'. A classificação climática de Köppen permaneceu inalterada para ambas as séries mantendo inalterada a fórmula climática de Lavras como Cwa. 


\section{REFERÊNCIAS BIBLIOGRÁFICAS}

ADGER, N.; AGGARWAL, P.; AGRAWALA, S.; ALCAMO, J.; ALLALI, A.; ANISIMOV, O.; ARNELL, N.; BOKO, M.; CANZIANI, O.; CARTER, T.; CASASSA, G.; CONFALONIERI, U.; CRUZ, R. C.; ALCARAZ, E. A.; EASTERLING, W.; FIELD, C.; FISCHLIN, A.; FITZHARRIS, B. B.; GARCÍA, C. G.; HANSON, C.; HARASAWA, H.; HENNESSY, K.; HUQ, S.; JONES, R.; BOGATAJ, L.; KAROLY, D.; KLEIN, K.; KUNDZEWICZ, Z.; LAL, M.; LASCO, R.; LOVE, G.; LU, X.; MAGRÍN, G.; MATA, L. J.; MCLEAN, R.; MENNE, B.; MIDGLEY, G.; MIMURA, N.; MIRZA, M. Q.; MORENO, J.; MORTSCH, L.; NIANG-DIOP, I.; NICHOLLS, R.; NOVÁKY, B.; LENURSE, L.; NYONG, A.; OPPENHEIMER, M.; PALUTIKOF, J.; PARRY, M.; PATWARDHAN, A.; LANKAO, P. R.; ROSENZWEIG, C.; SCHNEIDER, S.; SEMENOV, S.; SMITH, J.; STONE, J.; YPERSELE, J. P. van; VAUGHAN, D.; VOGEL, C.; WILBANKS, T.; WONG, P. P.; WU, S.; YOHE, G. Climate change 2007: climate change impacts, adaptation and vulnerability: fourth assessment report. Disponível em: 〈www.ipcc.ch >. Acesso em: 10 abr. 2007.

BRASIL. Ministério da Agricultura e da Reforma Agrária. Departamento Nacional de Meteorologia.
Normais climatológicas: 1961-1990. Brasília, DF, 1992. $84 \mathrm{p}$.

HANSEN, J.; RUEDY, R.; SATO, M.; LO, K. Global temperature trends: 2005 summation. 2006. Disponível em: <http:// data.giss.nasa.gov/gistemp/2005/>. Acesso em: 15 jan. 2007.

PEREIRA, A. R.; ANGELOCCI, L. R.; SENTELHAS, P. C. Agrometeorologia fundamentos e aplicações práticas. Guaíba: Agropecuária, 2002. 478 p.

THORNTHWAITE, C. W. An approach toward a rational classification of climate. Geography Review, [S.1.], v. 38, p. 55-94, 1948.

THORNTHWAITE, C. W.; MATHER, J. R. The water balance: publications in climatology. New Jersey: Drexel Institute of Technology, 1955. $104 \mathrm{p}$.

TUBELIS, A. A chuva e a produção agrícola. São Paulo: Nobel, 1988. 86 p.

VIANELLO, R. L.; ALVES, A. R. Meteorologia básica e aplicações. Viçosa: UFV, 1991. 449 p. 